\title{
Research into Knowledge Service Chain at Colleges and Universities
}

\author{
Haiyan Wang ${ }^{1, a}$, Xiwu Shao ${ }^{2, b *}$ and Yidan Shao ${ }^{3, b}$ \\ ${ }^{1}$ Higher Education Research Institute, Jilin Agricultural University, Changchun, China \\ ${ }^{2}$ College of Administration, Jilin Agricultural University, Changchun, China \\ ${ }^{3}$ China University of Mining and Technology, Beijing, Chian \\ awanghaiyan9588@126.com, bxiwushao@126.com, 'sydlareina@163.com \\ *The corresponding author
}

Keywords: Knowledge chain; Colleges and universities; Knowledge service chain; Core-competitiveness

\begin{abstract}
Ability to acquire and effectively utilize knowledge has already become one of the core elements for organizations to achieve success, and knowledge service is playing an important role in contemporary information society. Thus, to deeply analyze knowledge service chain at colleges and universities, promote the integration and effective configuration of colleges and universities' knowledge advantages and give the maximum play to the role of knowledge resources at colleges and universities has become a new issue for the good operation of knowledge services at colleges and universities and improvement of the service ability during the era of knowledge economy.
\end{abstract}

\section{Introduction}

The rapid development of knowledge economy makes knowledge capital become "the third resource" promote constant development of an organization after capital and labor. The ability to acquire and effectively utilize knowledge has already become one of the core elements for organizations to achieve success, and knowledge service is playing an important role in contemporary information society.

Zhang Xialin (2000) puts forward to apply the core competence of library and information work to the positioning of knowledge service, and then systematically elaborates on the concept, form and operation mode of knowledge service [1]. This paper has aroused wide attention of domestic and international library and information circles as well as the upsurge to study knowledge service. Yang Lin (2005) points out that "knowledge service" in the narrow sense refers to the various training, information and consulting services provided by institutions or organizations of the fourth kind of knowledge to the social public, as well as special services by using flexible service modes to fully utilize and mobilize the wisdom of knowledge owners to analyze, diagnose and solve specific problems; "knowledge service" in the broad sense refers to the various kinds of knowledge provided by institutions or organizations with various knowledge to the social public as well as a kind of service based on service functions and special knowledge [2]. At present, theoretical researches and practices aiming at knowledge services at colleges and universities mainly focus at library, but there are few researches into professional knowledge services at colleges and universities, such as teaching activities, scientific researches and daily administration, etc. and there are no systematic research into the knowledge service chain at colleges and universities. 
Since the reform and opening up, each college and university has fully used their own rich resources to provide the society with various services and become the leading force for regional innovation while playing an increasingly important role in national and regional development. Researchers at colleges and universities around the world and public research institutions are getting more and more patents, authorization fees and premium income, and they have even established spin-off companies with a sharp increase in academic entrepreneurial behaviors [3]. An in-depth analysis of colleges and universities' knowledge service chain so as to promote the integration and effective allocation of colleges and universities' advantages in knowledge and give maximum play to the utilization of colleges and universities' knowledge resources has become a new issue for the good operation of colleges and universities' knowledge service chain and improvement of their service abilities during the era of knowledge economy.

\section{Organization of the Text}

Analysis of Colleges and Universities' Knowledge Service Chain. Knowledge service chain at colleges and universities are on the premise that colleges and universities can satisfy users' different demands for knowledge, and it is an internalizing and externalizing process to fully utilize their own human resources, teaching and research equipment, books, and information through recognizing, capturing, processing, innovating, transmitting and expanding knowledge (see Fig. 1) so as to provide users with educational training, scientific research development and result transformation, information consulting, technical service, open libraries and other knowledge service, forming a chain structure. It is the basic activities for colleges and universities to innovate knowledge. According to the features of knowledge chain and the process of relevant knowledge services, the knowledge service chain at colleges and universities as shown in Fig. 2 is constructed.

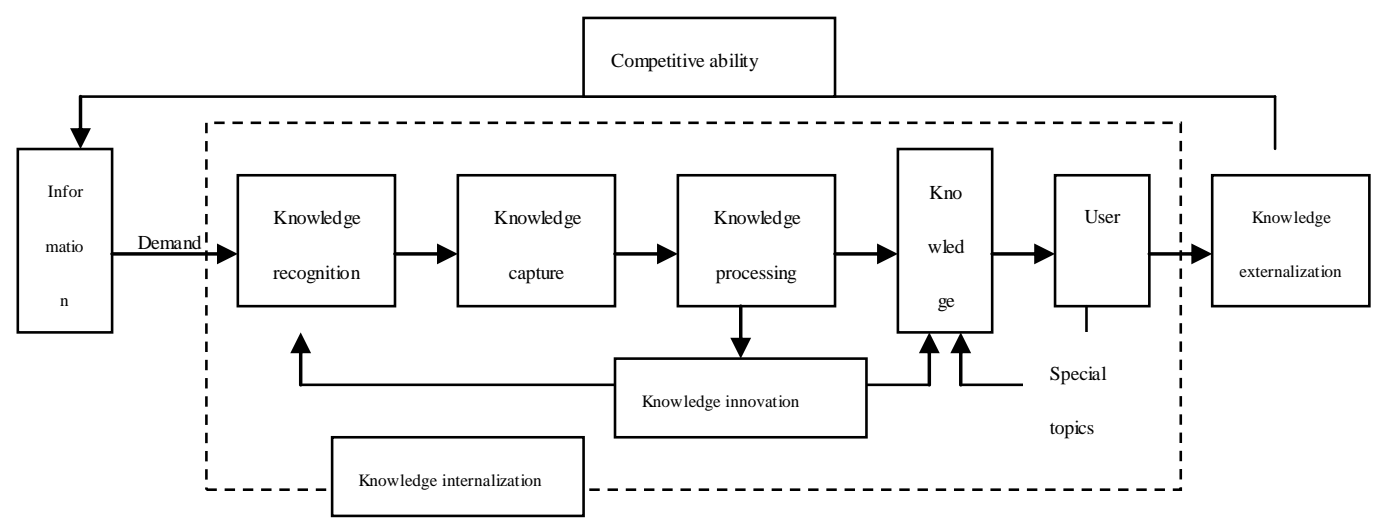

Figure 1. Chain structure of knowledge

Educational \& Training Knowledge Service Chain. The education and training of knowledge service chain is relying on the government special training funds, corporate training funds, internal training funds, make full use of university teachers, teaching and research equipment, books, information and other resources of their own, by the relevant experts in the field according to the needs of users, the face of the user directly, or to establish a knowledge base (database), or combined knowledge enterprise, knowledge services together to build the knowledge base (database) etc. to provide knowledge services to users, so as to broaden their horizons, change the 
concept of service chain, so as to solve the relevant problems of the grasp of the latest information, technology, method, see Fig. 3.

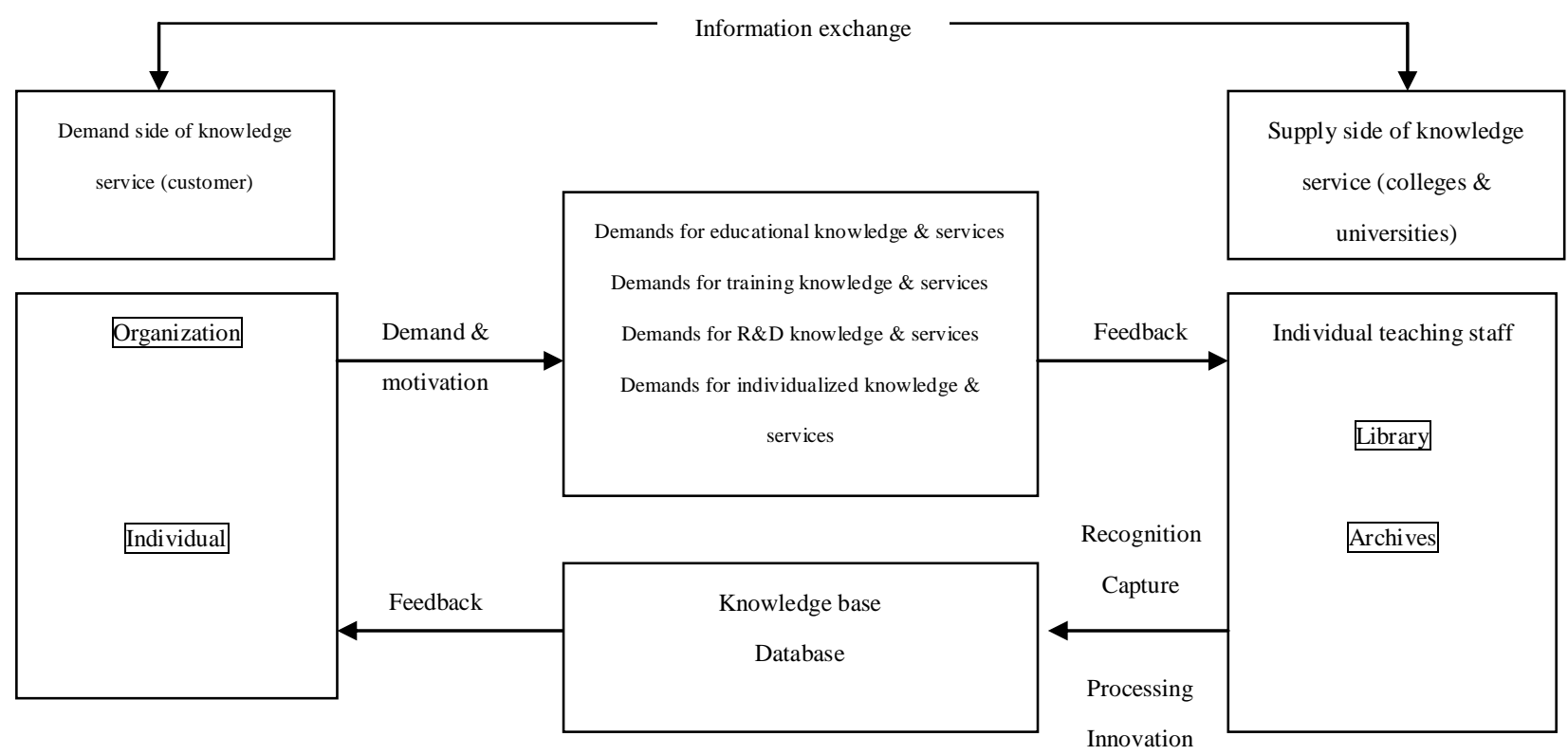

Figure 2. Knowledge \& Service Chain at Colleges \& Universities

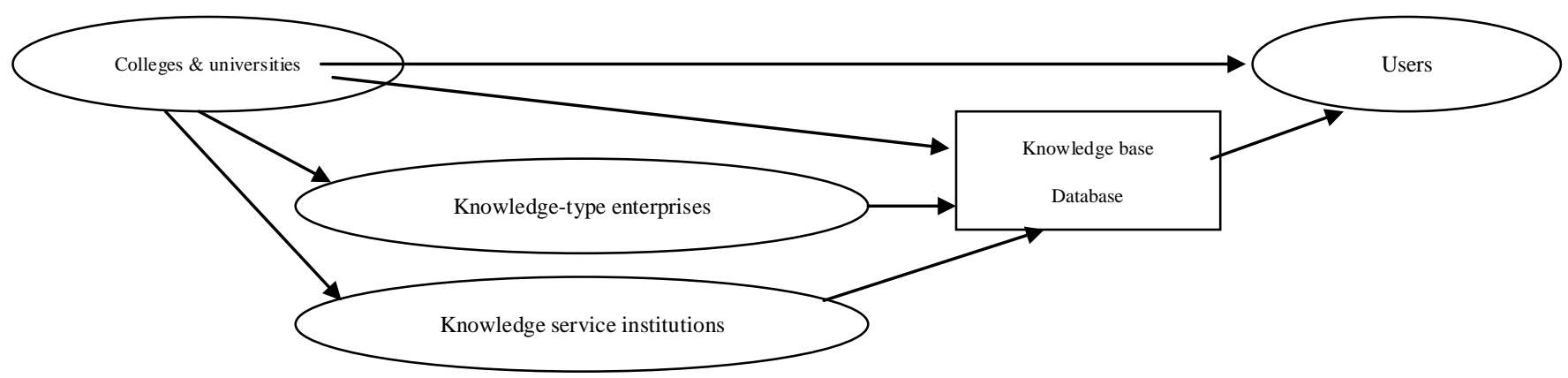

Figure 3. Education \& Training Knowledge Service Chain at Colleges and Universities

Reference \& Consulting Knowledge Service Chain. Reference \& consulting knowledge service chain refers to colleges and universities employ experts and professors directly or the relevant personnel at government, research institutes and enterprises have experienced consulting group consisting of, or to set up a hotline, or to establish a consultation center (platform), aiming at the existing problems in the production and life of the user to carry out knowledge service, see Fig. 4.

Individualized Knowledge Service Chain. Organizations or individuals demand for different types of knowledge services at different levels. In view of the internal public universities, teachers need the relevant knowledge in the activities of teaching and research, students in learning and thesis writing, thesis curriculum knowledge or research knowledge service needs, SDI service teaching and administrative staff required to enhance the management level of the external public access required; the related library document delivery service and interlibrary loan etc. Thus, the knowledge service chain to meet the individual needs is produced. Personalized 
knowledge service chain refers to the use of their own resources through books and archives, information mining, information push technology, search engine and other key technologies, related knowledge chain to provide services to internal and external public universities, see Fig. 5. Network service system of university library has abundant information resources, high-quality staff, perfect, strong organization, search, analysis, integration of information processing ability of knowledge and information, according to the information needs of the main innovation, the use of professional skills, professional knowledge service, to meet the demand of independent innovation and play its unique function of [5] university library knowledge service, fully play its important role in scientific-tech novelty retrieval, document retrieval, document delivery, information services, education and training, education, science and technology led to the development.

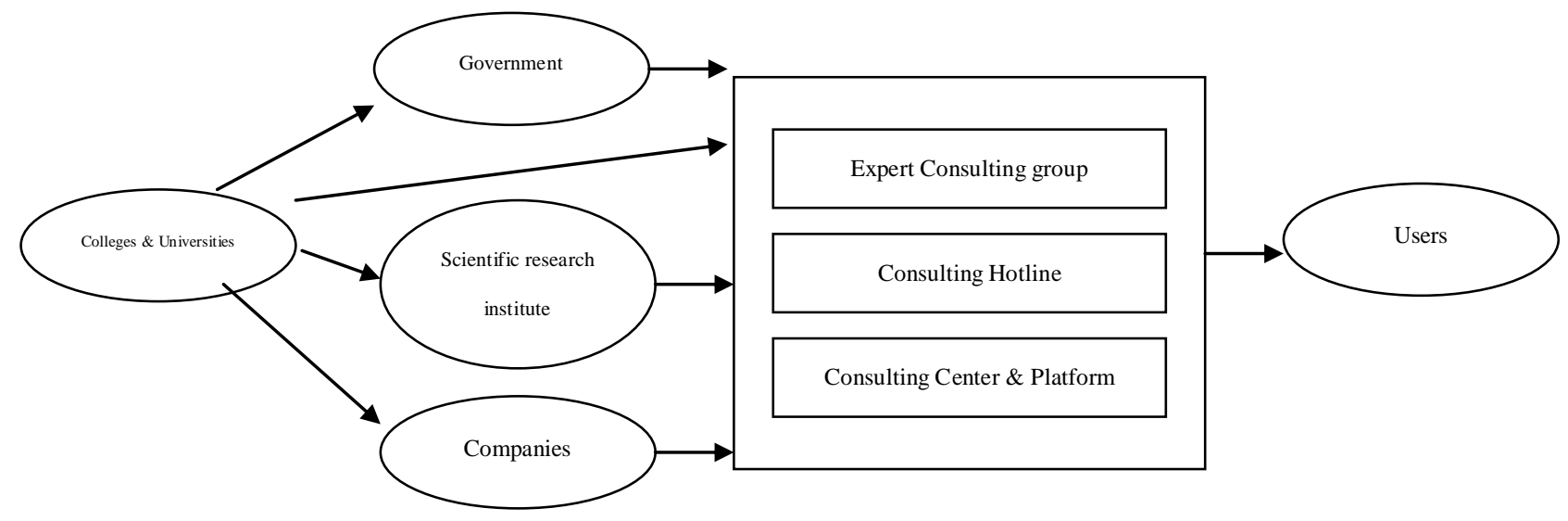

Figure 4. Reference \& Consulting Service Chain at Colleges and Universities

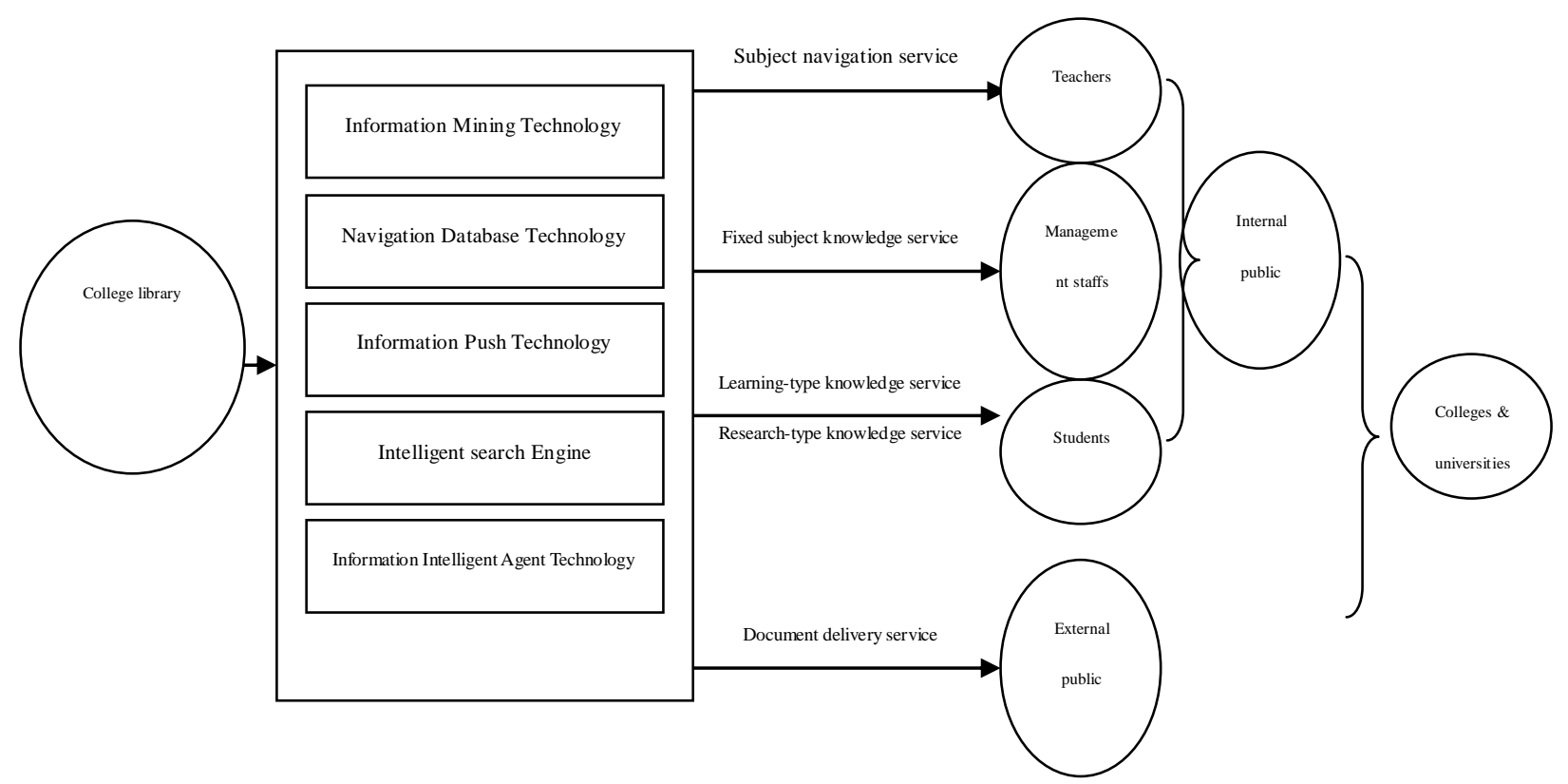

Figure 5. Individualized knowledge service chain at colleges and universities 


\section{Measures for Good Operation of Knowledge Service Chain at Colleges and Universities and Improvement of Service Ability}

Break Inter-school Barriers and Trade Barriers and Ensure Smooth Flow of Knowledge. Knowledge is a kind of resources that would not be worn and can be used repeatedly [6], and the orderly flow of knowledge is the crux of ensuring the smooth knowledge service chain. Therefore, it is necessary to revitalize colleges and universities' knowledge resources and break down various administrative and institutional barriers among departments and institutions based on ensuring resource owners' interests, and establish resource integration and sharing platform, organize knowledge associations and improve the return rate of knowledge investment.

Improve Knowledge Innovation Ability and Form Knowledge Advantages. Knowledge innovation is the source of new technology and new invention, and it is a revolutionary force to promote scientific and technological progress and economic growth. Knowledge innovation is not only conducive to the production and creation of individual knowledge within the organization, but also to promote the exchange and sharing of this individual knowledge, so as to improve the efficiency of organizational knowledge exchange and sharing. Therefore, colleges and universities should be in the knowledge chain, through the promotion of organizational knowledge sharing and communication, improve the efficiency of knowledge flow within the organization, enhance organizational learning and knowledge innovation ability, the core knowledge flow contribute to my knowledge advantage. At the same time, to strengthen the human capital management, stable staff, avoid the core knowledge outflow, attracting high content of knowledge workers to join the organization, to obtain adequate sources of knowledge innovation, ensure knowledge stock and flow of knowledge innovation in Colleges and universities.

Enhance Knowledge Service Cooperation in Administration, Production and Study. Isolated knowledge chain does not exist, and any organization is closely associated with various external organizations based on knowledge flow in the radiation form. The more the associations are, the higher level and more effective knowledge flow is [7]. The diversification of decision knowledge service must strengthen cooperation, accurate positioning, and carry out their duties. The government should make good policies, such as concretely delineated in the intellectual property ownership, stakeholder distribution, scientific research personnel incentives, knowledge transfer and other aspects, set up a special fund to promote knowledge service standardization and healthy development. Enterprises should improve the ability of independent innovation; colleges and universities should give full play to the advantages of disciplines, technology and talent, and actively promote the creation of knowledge, transfer speed.

Promote Further Cooperation among College Libraries. John Nesbit emphasizes knowledge has the function of enhancing cooperation, and the overall value is larger than the sum of each part [8]. Knowledge service is open, and different colleges and universities can exchange knowledge of the same or similar subjects to make their own knowledge supply chain integrated into the specific system of national knowledge supply chain [9]. Libraries of different colleges and universities should enhance cooperation and form knowledge association to establish a stable, efficient and professional knowledge service team and promote the integration of external knowledge and internal knowledge so as to improve the overall strength of library alliance. 


\section{References}

[1] Zhang Xiaolin. Go to Knowledge Service: Seek Growth Point of Library Intelligence Work in New Century [J]. Journal of China Library, 2000(5):

[2] Yang Lin. Marketing Reflection on Knowledge Service Industry [J]. Business Times, 2005(18):40.

[3] Li Daling. Statistics and Analysis of Knowledge Service Research in 2000-2009 [J]. Intelligence Science, 2012(1):68-71.

[4] Peng Jisheng, Sun Wenxiang, Lin Wei, etc. Reflection on the Function Positioning of Scientific Innovation at Chinese Colleges and Universities in Social and Economic Development [J]. Research and Development Management, 2006(1): 109-115.

[5] Peng Shenglin, Zhan Yiqing, Zhou Helin, etc. Exploration and Practice of Promoting Local Social Development with Colleges and Universities -Take the Example of Developing Hunan Through Science and Education at Central South University [J]. Modern College Education, 2008(1):80-85.

[6] Wang Hongyu. Knowledge Service Functions at College Libraries in Regional Autonomous Innovation and Strategies of Realization [J]. Journal of Henan College of Finance and Taxation, 2011(12):72-73.

[7] Li Changling. Knowledge Supply Chain and Management [J]. Intelligence Magazine, 2004(11):9-11.

[8] John Naisbitt, Huang Mingjian (translator). Great Trend - Ten New Directions Changing Our Life [M]. Beijing: China Social Science Press, 1984.

[9] Li Zuohua. Research into Library Knowledge Service at Colleges and Universities from the Perspective of Knowledge Supply Chain [J]. College Library Work, 2009(2):57-59. 